\title{
O PAPEL DAS FERRAMENTAS BIM DE INTEGRAÇÃO E COMPARTILHAMENTO NO PROCESSO DE PROJETO NA INDÚSTRIA DA CONSTRUÇÃO CIVIL
}

\section{The role of BIM integration and sharing tools in the design process of the built environment}

\author{
Regina Coeli Ruschel ${ }^{1}$, Cesar Augusto Vieira Valente ${ }^{2}$, Eduardo Cacere ${ }^{3}$, \\ Sérgio Ricardo Souza Leal de Queiroz ${ }^{4}$
}

Recebido em 07 de novembro de 2013; recebido para revisão em 05 de dezembro de 2013; aceito em 10 de dezembro de 2013; disponivel on-line em 27 de dezembro de 2013.

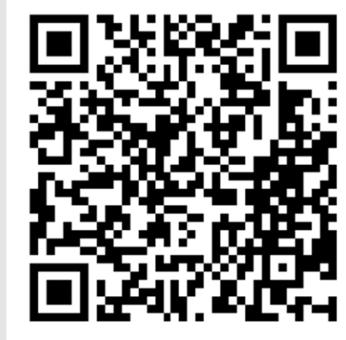

\section{PALAVRAS CHAVES:}

BIM;

Gestão de projetos; Integração de projeto; Compartilhamento de modelo de informação;

Construção civil.

\section{KEYWORDS:}

BIM;

Design management;

Design integration;

Information modeling sharing;

Building construction.

\begin{abstract}
RESUMO: Em projetos complexos, há uma grande necessidade do envolvimento das diversas disciplinas de projetos expresso no fluxo contínuo de troca de informações e interdependência entre envolvidos. Neste contexto, é verrificado que a indústria da construção civil é carente de uma sistemática eficiente de gerenciamento desses processos de comunicação e troca de informações, gerando conflitos, retrabalhos e desperdícios. Um dos propósitos do Building Information Modeling (BIM) é atender a troca contínua de informações ao longo da gestão do ciclo de vida do empreendimento. Este artigo apresenta um estudo exploratório que objetivou desvendar a consolidação do modelo de informação no projeto colaborativo mediado pelo BIM. Para tal, desenvolveu-se o mapeamento entre as atividades e responsabilidades na gestão de projeto de Arquitetura, Engenharia e Construção (AEC) e as funcionalidades de ferramentas de integração e compartilhamento. Buscou-se identificar na descrição das ferramentas, recursos para apoio às funções de gestão de projeto, coordenação e compatibilização. Deste mapeamento, esquemas de colaboração são então vislumbrados e discutidos explanando assim processo para a consolidação do modelo de informação por meio da colaboração em BIM.
\end{abstract}

ABSTRACT: In complex projects, there is great need for the involvement of the various disciplines of design expressed in the continuous flow of information exchange and interdependence involved. In this context, it is found that the construction industry is need of an efficient systematic management of these processes of communication and information exchange, generating interference, rework and waste. One purpose of Building Information Modeling (BIM) is to meet the continuous exchange of information throughout the management life cycle of the enterprise. This paper presents an exploratory study aimed to unravel the consolidation of the information model in collaborative project-mediated BIM. To this end, we developed the mapping between activities and responsibilities in project management Architecture, Engineering and Construction (AEC) and features tools for integrating and sharing. We tried to identify the description of the tools, resources to support the functions of project management, coordination and harmonization. This mapping, collaborative schemes are then discussed and envisioned just explaining the process to consolidate the information model through collaborative BIM.

\footnotetext{
* Contato com o autor:

${ }^{1}$ e-mail : ruschel@fec.unicamp.br (R. C. Ruschel)

Livre docente Doutora em Engenharia Elétrica, docente da Faculdade de Engenharia Civil, Arquitetura e Urbanismo da UNICAMP.

22e-mail : cesar.valente@ifsp.edu.br (C. A. V. Valente )

Mestre em Habitação, docente do Instituto Federal de Educação, Ciência e Tecnologia de São Paulo.

${ }^{3}$ e-mail : educacere@gmail.com (E. Cacere)

Eng. Civil, graduado pela Faculdade de Engenharia Civil, Arquitetura e Urbanismo da UNICAMP.

${ }^{4}$ e-mail : sergio.souza.queiroz@terra.com.br (S. R. S. L de Queiroz )

Bacharel em Ciência da Computação, mestrando do Programa de Pós-graduação em Engenharia Civil da UNICAMP. 


\section{INTRODUÇÃO}

A indústria da Construção Civil possui um grande papel no desenvolvimento do país. Do ponto de vista econômico destaca-se pela quantidade de atividades que interveem em seu ciclo de produção, gerando consumos de bens e serviços de outros setores, como do social através da capacidade de absorção da mão-de-obra. Ao analisar o processo produtivo sintetizado por Picchi (2003), esse seria caracterizado pela existência de muitas etapas interdependentes e com um nível de gerenciamento global daquele quase inexistente. Além disso, Bertelsen (2002) enfatiza o predomínio das incertezas e desperdícios. Os envolvidos no processo, tais como projetistas, construtores, fornecedores e colaboradores, em sua grande maioria, trabalham em ambientes separados e com intensa utilização de informações. Essa falta de cooperação entre os envolvidos nos trabalhos, normalmente, provocam falta de eficiência e produtividade (DAWOOD et al., 2002) e esse é um problema que as empresas vêm enfrentando, ou seja, a dificuldade em visualizar corretamente o planejamento de uma obra no espaço (HEESOM; MAHDJOUBI, 2003). Fica clara a necessidade da valorização da integração entre os agentes, minimizando a possibilidade de erros, retrabalhos, ineficiência e defeitos.

A integração de projetos de construção civil depende da transferência e compartilhamento da informação. A tentativa de solução para este cenário prescinde de recursos que tenham capacidade de adequar a relação entre os agentes participantes do processo de elaboração do projeto. A inserção de Tecnologias da Informação (TIs) nos diversos setores da indústria da construção tem propiciado agilidade nos procedimentos $\mathrm{e}$ processos, desde a concepção dos projetos, incluindo o gerenciamento, se tornando um elemento estratégico para as corporações (BETTS, 1999 apud JACOSKI; LAMBERTS, 2002).

O uso eficaz da $\mathrm{TI}$ como elemento estratégico para as corporações vai além da ideia de ferramenta de produtividade, sendo muitas vezes fator crítico de sucesso do negócio. 0 caminho para este sucesso não está relacionado somente com equipamentos, programas computacionais e de comunicação utilizados ou com metodologias de desenvolvimento, mas com o alinhamento da $\mathrm{Tl}$ à estratégia e às características da empresa e de sua estrutura organizacional (LAURINDO et al., 2001).

É grande o potencial benefício do uso de tecnologias para gerenciar informações de projeto e a adoção de sistemas colaborativos para apoio à gestão do processo de projeto na construção civil é uma realidade (ACHTEN; BEETZ, 2009). Entretanto, ambientes de colaboração (em intranets ou na internet) ainda apresentam deficiências no suporte a coordenação e comunicação (NITITHAMYONGE; SKIBNIEWSKI, 2004). A evolução dos conceitos em Building Information Modelling (BIM) e a adoção dos mesmos pelas empresas de projeto $\mathrm{e}$ construção civil se tornaram mais intensas motivando o desenvolvimento e a utilização das ferramentas de integração e o compartilhamento de modelos de informação da construção (GU; LONDON, 2010). Estas ferramentas apresentam uma grande melhoria nos canais de comunicação, colaboração e melhoria contínua do processo de projeto.

Entretanto, informações de baixa qualidade podem prejudicar a tomada de decisão no processo de projeto na cadeia produtiva, principalmente ao quesito referente ao controle da produção. Os sistemas de informação normalmente utilizados para suporte e para controle da produção são limitados para a geração de informações abrangentes e integradas (FAVARETTO, 2007). Um importante benefício para minimizar riscos e auxiliar os gerentes a obter eficácia nos seus processos de controle (projeto ou produção) é a escolha correta de ferramentas de TI que bem selecionadas podem sistematizar as soluções em projeto, como também alinhar as metas da organização (MORAES; LAURINDO, 2003).

\section{OBJETIVO E MÉTODO}

Este artigo apresenta um estudo exploratório que objetivou desvendar a consolidação do modelo de informação no projeto 
colaborativo mediado pelo BIM (Figura 1). Para tal, desenvolveu-se o mapeamento entre as atividades de consolidação na gestão de projeto de AEC e as funcionalidades das ferramentas de integração BIM. Buscou-se identificar na descrição das ferramentas de integração e compartilhamento de modelos, recursos para apoio nas funções de gestão de projeto, coordenação e compatibilização. Deste mapeamento esquemas de colaboração foram então vislumbrados.

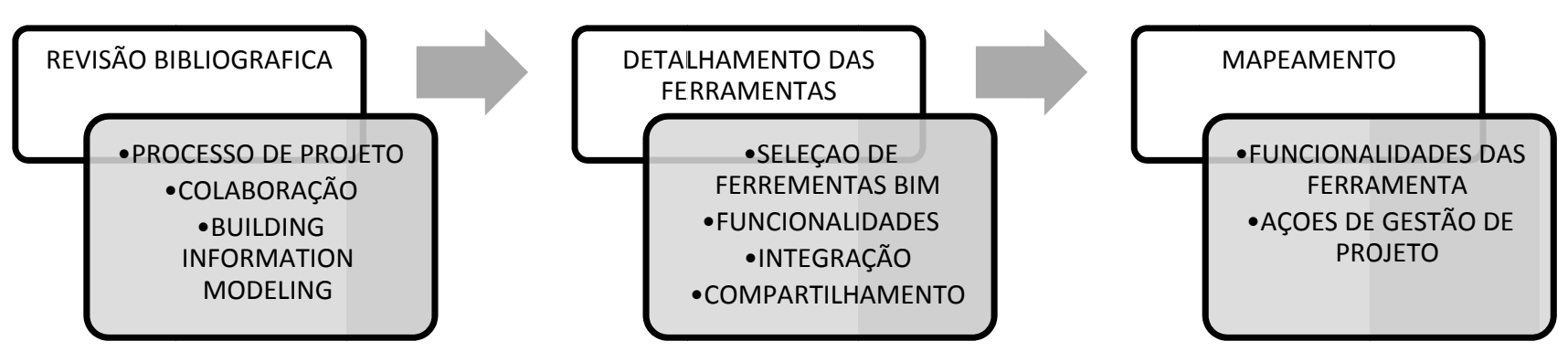

FIGURA 1: Delineamento do estudo exploratório.

\section{REVISÃO BIBLIOGRÁFICA}

\subsection{PROCESSO DE PROJETO NA CONSTRUÇÃO CIVIL}

De acordo com Silva e Souza (2003, p. 6061), o processo de projeto é um conjunto de atividades com fases pré-estabelecidas para desenvolver produtos e serviços de acordo com as necessidades dos clientes. Assim, no processo de projeto as fases e atividades tem início com o planejamento estratégico, seguido pelo planejamento do empreendimento, a concepção do produto, o desenvolvimento do produto e a entrega final. Corre em paralelo ao desenvolvimento do produto a obra, com o acompanhamento técnico dos projetistas, coleta de dados e elaboração de projeto as-built e a elaboração dos documentos para manual do usuário. Finalizada a obra tem-se a entrega das unidades e a avaliação pós-ocupação. 0 ciclo do processo de projeto se fecha com a retroalimentação ao planejamento estratégico de novos projetos (Figura $2 \mathrm{~A}$ ).

A fase de desenvolvimento do produto envolve grande interação entre os participantes do processo incluindo etapas importantes com o desenvolvimento do anteprojeto, do projeto legal, dos projetos pré-executivos, executivos e de detalhamento e projeto de produção (Figura 2B). Segundo Silva e Souza (2003), no anteprojeto os projetistas desenvolvem a arquitetura, a estrutura e estudos preliminares de outras disciplinas (vedações, paisagismo, sistemas prediais, fundações, impermeabilização, entre outros), sob controle rigoroso de informações. O projeto préexecutivo é consolidadı segundo análise da coordenação em relação a todos os projetos. Ocorre nesta etapa necessidade de muita interação e comunicação entre projetistas envolvidos no processo. Esta interdependencia é denotada graficamente (Figura 2B) pelas ligações entre as caixas que representam o desenvolvimento dos projetos pré-executivos das múltipas disciplinas envolvidas no processo. Entretanto, já no desenvolvimento do projeto executivo observa-se, ainda na mesma figura, interação mínima entre os agentes envolvidos. A impressão que se têm é que todas as interferências foram solucionadas na etapa anterior e que nesta etapa a grande ênfase está no detalhamento. 0 esquema que representa o processo de projeto na fase de projeto executivo demonstra pouca comunicação com grande paralelismo de atividades entre agentes. Destaca-se ao longo do processo de projeto a necessidade ou momento de consolidação desenvolvidos e geridos pela coordenação.

Na década de 60, era comum as empresas desenvolverem projetos e os executarem. O corpo técnico conseguia trabalhar de forma conjunta; a distância entre projetistas e construtores, era pequena; o contato direto com a prática de construção proporcionavia aos projetistas uma 
ampla visão das necessidades das diversas especialidades e das questões de construtibilidades. Esse ambiente gerava diversos ganhos quanto às questões de comunicação e coordenação das atividades. Segundo Coelho e Novaes (2008), com o passar do tempo, os construtores ficaram mais distanciados das atividades de projeto e os projetistas ficaram mais longe da execução dos sistemas por eles projetados. Esta perda de elos entre os participantes, fez com que a atividade construtiva passasse a ter altos índices de desperdício.

O mercado identificou a falta desse elo, e percebeu a importância das atividades de coordenação e compatibilização, originada pelo cisalhamento entre projeto e execução. Nos últimos anos, o mercado da construção civil tem se tornado cada vez mais competitivo e exigente. Os projetos atuais apresentam alta complexidade e uma grande necessidade de planejamento - desdobrado em diversos níveis -, e sua qualidade está diretamente relacionada com seu desempenho em relação às necessidades dos clientes que o utilizarão, e dos clientes internos participantes do seu processo de desenvolvimento. Compõe esse processo os projetos de arquitetura, estrutura, instalações hidráulicas e elétricas, telefonia, incêndio, paisagismo, comunicação visual, entre outros. Para assegurar que as equipes de projeto, incluindo os representantes do contratante, possam chegar ao final de seu trabalho atingindo os resultados esperados, são identificados três papeis essenciais: gerenciamento de projeto; coordenação técnica de projeto e compatibilização de projeto (SILVA; SOUZA, 2003).

O gerenciamento de projeto é caracterizado pelo desenvolvimento das atividades de planejamento e organização das operações. Geralmente é identificado pelo profissional, cujas responsabilidades envolvem: identificação das atividades necessárias ao desenvolvimento do projeto; planejamento e controle do processo considerando tempo e recursos; aprovação de produtos intermediários e a liberação para início das fases de projeto; e encaminhamento e acompanhamento das providências operacionais para o desenvolvimento de projeto (SILVA; SOUZA, 2003, p. 89).

A coordenação técnica está ligada aos aspectos do processo, planejamento, coordenação e gestão das soluções (engenharia, arquitetura ...). O conjunto de ações deve garantir as soluções desenvolvidas pelos projetistas de diferentes especialidades, sejam congruentes com as necessidades e objetivos do cliente, compatíveis entre si e com a cultura construtiva das empresas construtoras. As atividades desenvolvidas são: estabelecimento de diretrizes e parâmetros técnicos do empreendimento, do produto, do processo de produção e das estratégias da empresa incorporadora/construtora; identificação e caracterização das interfaces técnicas; coordenação do fluxo de informações entre intervenientes; análise das soluções técnicas e do grau de solução global atingida e tomada de decisões sobre as necessidades de integração das soluções (SILVA; SOUZA, 2003, p. 89).

A compatibilização de projetos é a atividade de gerenciar e integrar projetos correlatos, visando o ajuste entre os mesmos e conduzindo para a obtenção dos padrões de qualidade determinada pela obra. Segundo Solano (2005), a compatibilização compreende cinco esferas: estratégica do projeto, mercalogica, de viabilidade econônica, construtibilidade e fluxo da operação. Segundo Graziano (2003), compatibilidade é definida como atributo do projeto, cujos componentes dos sistemas que ocupam espaços não conflitante entre si e, além disso, os dados compartilhados tenham consistência e confiabilidade até o final do processo de projeto e obra. A compatibilização para Santos, Powell e Formoso (1998) é realizada através da ação projetual, com verificação da sobreposição e da identificação de interferências entre as mesmas. Rodríguez (2005) define a compatibilização de projetos como a análise, verificação e correção das interferências físicas entre as diferentes soluções de projeto de uma edificação. Observa-se consenso na literatura sobre a necessidade de verificar interferências físicas e discutir informações que interligam as características de cada projeto. 


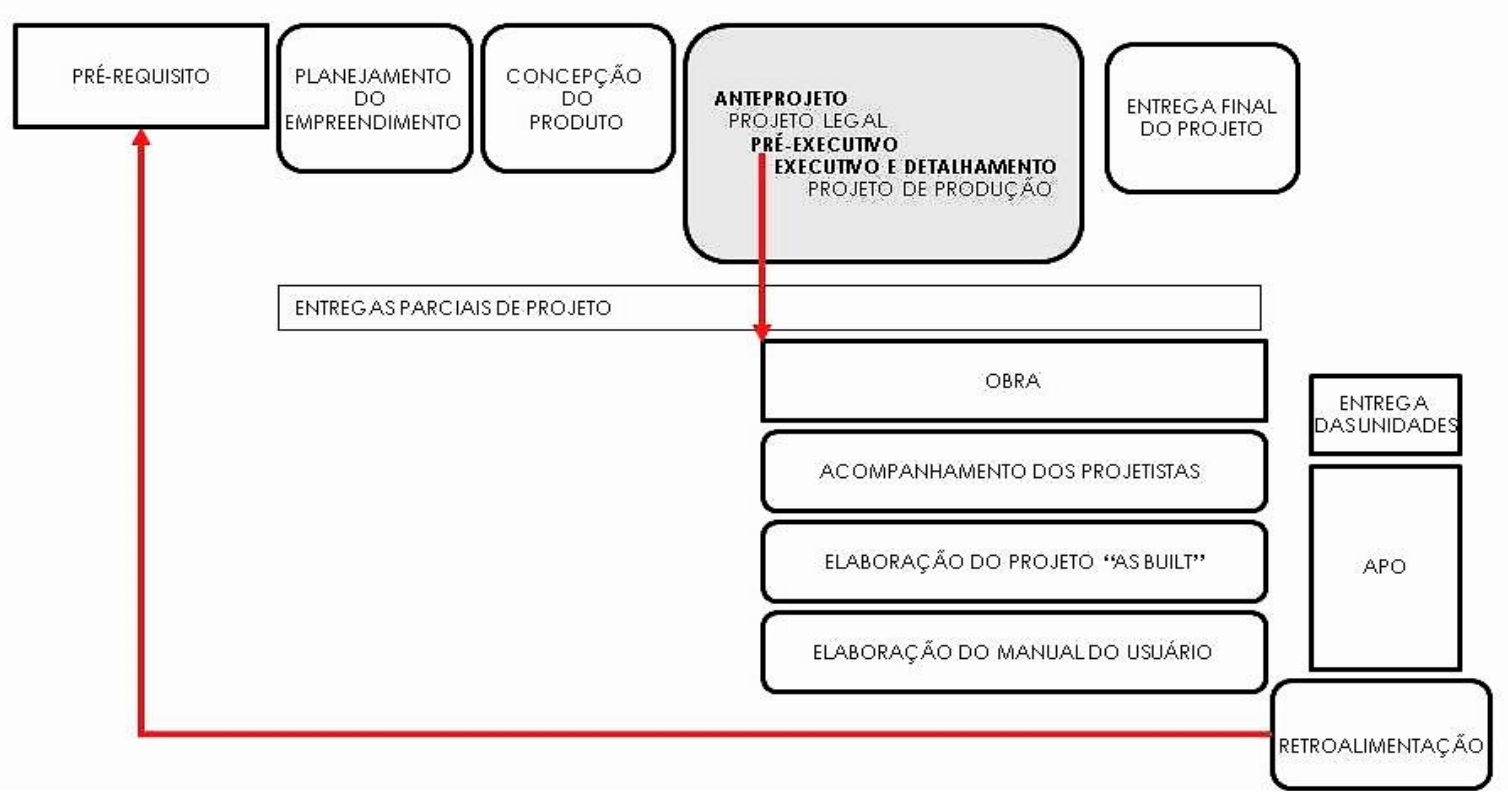

(A)

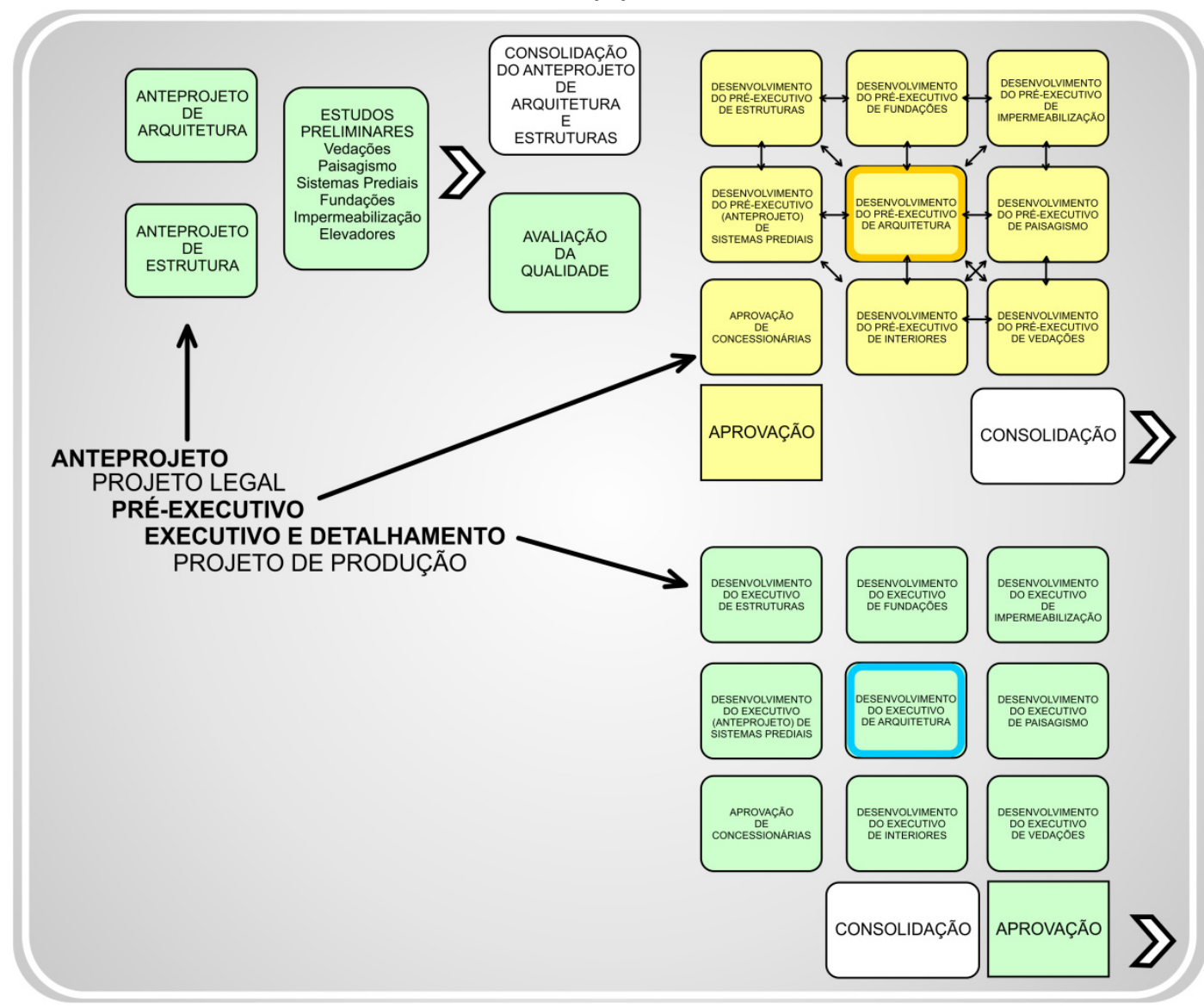

(B)

FIGURA 2: Fases do processo de projeto: (A) ciclo completo e (B) detalhamento do esquema de colaboração no desenvolvimento do anteprojeto, projetos pré-executivos e executivos. Fonte: Adaptado de Silva e Souza (2003). 
Para discutir neste trabalho sobre cenários de colaboração, parte-se da Figura 3 que é uma representação alternativa da Figura 2B. Nesta representação os agentes são identificados pelos retângulos em diferentes cores. Os modelos 3D ou desenhos 2D, que são trocados entre os agentes, são representados por circunferências com cores correspondentes de cada agente. A coordenação é responsável pela consolidação do projeto; portanto, pela integração dos desenhos ou modelos.
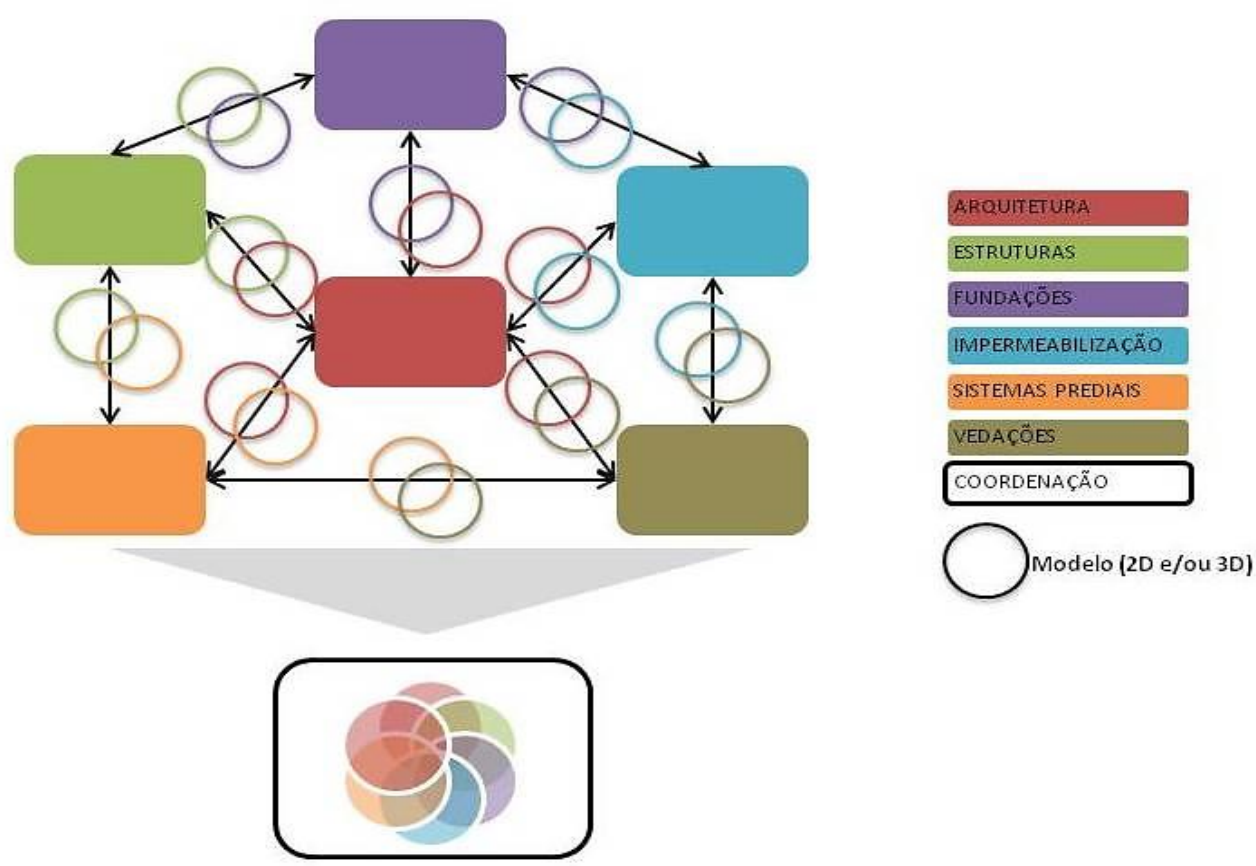

FIGURA 3: Esquema de colaboração para a fase de desenvolvimento do produto.

\subsection{PROJETO COLABORATIVO E INTEGRADO}

De acordo com Simoff e Mary (2000), Kvan (2000), Kalay (2006) e Hamid (2007) o projeto de arquitetura, engenharia e construção (AEC), contido na indústria da construção civil, é um processo social que muitas vezes envolve organizações distribuídas, inclusive geograficamente, com profissionais de múltiplas habilidades, além de leigos com seus próprios fundamentos e visões sobre o projeto exigido, requerendo, efetiva colaboração. Entretanto, por que quando se refere a projeto colaborativo parece se estar abordando algo novo, sendo diferente do que é comumente executado entre os profissionais da AEC? Segundo Kvan (2000), isto se deve ao fato de que o projeto colaborativo em AEC é praticado por meio de ações paralelas de especialistas, executadas entre atividades conjuntas de negociação e avaliação. Desta forma, a atividade de projeto é discreta, individual e paralela, acoplada fracamente. Projetistas agem como especialistas individuais abordando fatores de projeto a partir de suas perspectivas. Busca-se constantemente vencer este cenário de colaboração segmentada.
Em recente e extensa revisão bibliográfica, Achten e Beetz (2009) observaram que pesquisas sobre projeto colaborativo desenvolvem-se em torno dos temas: suporte, metodologia, teoria, modelos, tecnologia, educação e outros. Interessa-nos os temas de modelo e suporte, pois englobam métodos e ferramental para o compartilhamento e integração da informação que são vitais para a atividade de consolidação de projeto na gestão, coordenação e compatibilização de projeto. Pesquisas sobre modelos de colaboração visam descrever a natureza do processo colaborativo enfatizando sua gestão. Pesquisas sobre o suporte ao projeto colaborativo abordam o desenvolvimento de aplicativos como: (i) ambientes 3D virtuais para desenvolvimento e discussão de modelos, (ii) aplicações assíncronas e síncronas de comunicação, (iii) comunidades sociais e (iv) aplicativos específicos para apoio ao processo colaborativo.

Neste sentido, Cambiaghi et al. (2002) exemplifica uma contribuição em termos de modelo de colaboração, pois propõe diretrizes gerais para intercambialidade entre projetista, 
construtoras e clientes de projetos no contexto Computer Aided Design (CAD) em duas dimensões (2D). As diretrizes eram baseadas: em padronização de nomenclatura de diretórios, arquivos e layers; na adoção de coordenada absoluta padrão entre agentes de projeto; no desenvolvimento de arquivos base 2D e na utilização do recursos de CAD de referência externa para composição de pranchas de desenho. Entretanto, este método era extremamente dependente da disciplina do projetista para segui-lo sem uma tecnologia que levasse naturalmente o projetista para seguir o método.

Em resposta a necessidade de colaboração implícita no modelo de trabalho e não decorrente de uma disciplina imposta ao projetista tem-se o paradigma de Building Information Modeling (BIM).

\subsection{BIM - MODELAGEM DA INFORMAÇÃO NA CONSTRUÇÃO}

Segundo Eastman et al. (2008, p. 13), BIM

é uma tecnologia de modelagem e processos associados para produzir, comunicar e analisar edifícios. A idéia que sustenta o uso de BIM na indústria de $A E C$ está fundamentada no conceito de interoperabilidade e na colaboração entre os diversos profissionais. Desta forma, o projeto colaborativo em AEC suportado pelo paradigma de BIM é fundamentado no desenvolvimento do modelo de informação compartilhado, na utilização de verdadeiros elementos digitais de AEC disponibilizados em bibliotecas de classes de objetos, na parametrização de todas as informações do edifício (propriedade e comportamento), na geração automatizada da documentação e no vínculo bidirecional entre documento e modelo.

Para tal, faz-se diferenciação entre recursos computacionais que suportam a colaboração existente entre projetistas de uma mesma disciplina (colaboração interna) e entre projetistas de diferentes disciplinas (colaboração externa).

BIM pode ser compreendido como um processo de manutenção de um repositório de todas as informações relevantes a um edifício ou construção do projeto, ao longo das diferentes fases do ciclo de vida do projeto (Figura 4A). $O$ processo geralmente se inicia com a concepção arquitetônica em forma mais livre e modelos topológicos. Num processo cíclico e recursivo de análise, síntese e avaliação o modelo é transformado e aos poucos é melhor definido e assim tipado (ANDRADE e RUSCHEL, 2011). As informações podem ser usadas em combinação ou separadamente, mas não de forma isolada, no sentido de que elas estarão sempre sujeitas a alguma integração e ao cruzamento de dados (Figura 4B).

O conjunto de ferramentas computacionais que permitem BIM é compreendido por aplicativos de autoria e integração (TOBIN, 2008). Existem dois tipos de ferramentas de autoria: as de modelagem e as de análise ou simulação sobre o modelo. Exemplos mais conhecidos de ferramentas de autoria para modelagem paramétrica BIM são: ARCHICAD, REVIT (Architecture, Structure e MEP) e VECTOR WORK. Já ferramentas como ECOTEC e ROBOT são exemplos de ferramentas de autoria para análise e simulação, do desempenho ambiental e estrutural respectivamente.

Os aplicativos de integração permitem a integração a múltiplos modelos, como também o compartilhamento dos mesmos entre agentes. Ferramentas que integram modelos tem a função de compor um modelo a partir de outros e fazer a compatilibilização entre os mesmos. Esta compatibilização pode ser física, temporal ou dinâmica. Finalmente, têm-se as ferramentas que permitem a troca de modelos de informação entre os intervenientes por meio do compartilhamento dos mesmos.

No esquema da Figura $4 \mathrm{~B}$ os diferentes agentes no processo de projeto são representados pelas diferentes cores, as ferramentas de autoria de modelagem e simulação trabalham lado a lado no processo de projeto por agentes específicos. A consolidação dos respectivos modelos de informação gerados e compartilhados é integrada no centro do processo. 


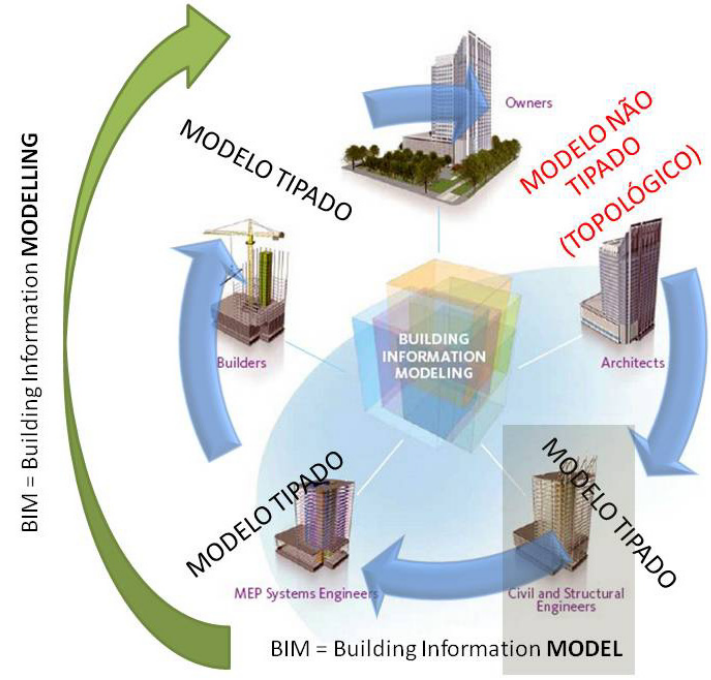

(A)

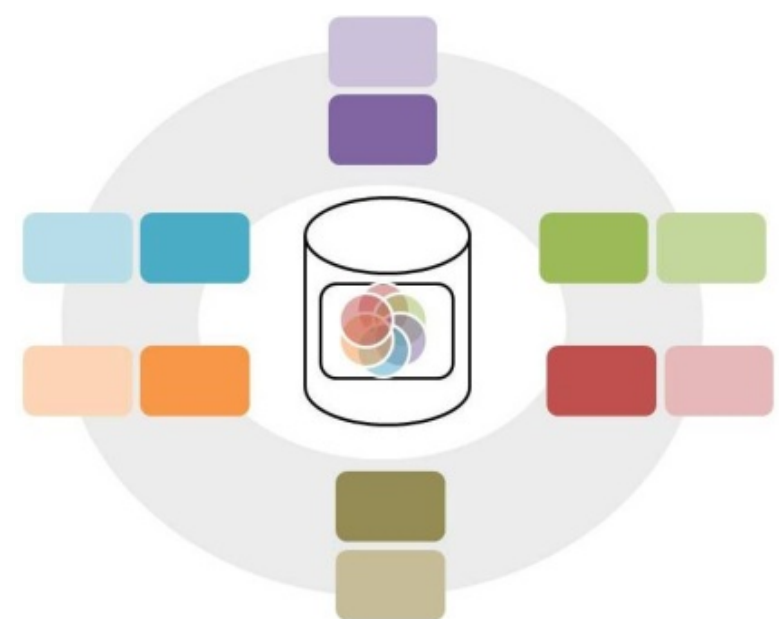

(B)

FIGURA 4: (A) Processo BIM ao longo das diferentes fases do ciclo de vida (modelagem) e BIM englobando múltiplos modelos do topológico ao tipado e (B) esquema representando a consolidação de múltiplos modelos de informação no processo BIM.

\section{RESULTADOS}

\subsection{FERRAMENTAS INTEGRADORAS DE MODELOS}

O conceito de BIM pressupõe que, a partir de múltiplos modelos de informação, os agentes sejam capazes de extrair todas as informações e desenhos necessários, além de que, quando se modifica um objeto, essa mudança se reflita em todo o conjunto. Neste contexto, faz-se necessário as ferramentas integradoras que, oferecem recursos para a consolidação de todos os modelos BIM pertinentes a um projeto, (ex: estrutura, arquitetura, HVAC, eletro-mecânica, etc) criando um modelo composto. As ferramentas integradoras devem fornecer dispositivos de navegação pelo modelo, interação com o mesmo e análise de interferências.

O conceito por trás desta abordagem de integração é a possibilidade de compatibilização entre todas as disciplinas envolvidas, através de recursos de navegação e emissão de relatórios, que fornecem suporte suficiente em tomadas de decisões. As ferramentas integradoras ainda permitem a adição do tempo, em forma de cronograma, simulando a evolução da construção. Faz assim a compatibilização do modelo físico virtual com o modelo temporal da construção. Esta função, além de identificar os conflitos geométricos, também busca identificar choques em função do tempo e lacunas na programação. Grandes equipamentos (gruas, elevadores provisórios, andaimes, etc.) usados na construção podem ser associados a atividades do planejamento e serem visualizados ao longo do tempo, permitindo a detecção de interferências no andamento da obra.

Por possibilitar a consolidação de múltiplos modelos - geométricos e temporais estas ferramentas são denominadas de simulação 4D. Para Eastman et al. (2011, p. 285-288) os benefícios do desenvolvimento dos modelos 4D são: visualização e comunicação, integração de agentes, estudo de logística, suporte a coordenação e acompanhamento do planejamento. Estes autores enumeram as seguintes ferramentas com estas funcionalidades: Tekla Structures Insight, Digital Project, ProjectWise Navigator V8i,Visual Simulation, Navisworks Simulate, Synchro Professional Pi, Virtual Construction. Selecionou-se dentre estas, para este estudo, as ferramentas NavisWorks e Synchro. Estas são ferramentas similares mas de fornecedores com características diferentes, enquanto a primeira tem origem na construção civil a segunda provém da engenharia de produção. Incluiu-se uma terceira ferramenta neste estudo, Solibri Model Checker, pois faz 
integração e estudos de integridade em modelos BIM de formato aberto. Esta ferramenta é caracterizada por Eastman et al. (2011) como uma ferramenta de simulação para análise funcional. Outro critério utilizado para determinar esta seleção é que as ferramentas NavisWorks e Synchro dão suporte à colaboração externa, i.e., entre diferentes agentes no processo de projeto. Já a ferramenta Solibri dá suporte à colaboração interna, entre agentes da mesma disciplina.

O NAVISWORKS ${ }^{1}$ é a solução da AutoDesk para integração de modelos. Trata-se de uma ferramenta completa de revisão de projeto para análise, simulação e comunicação. Em termos da capacidade de importação de arquivos é possível integrar múltiplos modelos em variados formatos em um único arquivo integrado. Desta forma, os modelos das diversas disciplinas podem ser combinados entre si, formando um arquivo único e seguro. Possui funcionalidades de gerenciamento e detecção de interferências que auxiliam a prevenção de problemas de construtibilidade antes do início da construção, minimizando atrasos e retrabalho dispendiosos. A reorganização dos componentes do modelo não é possível por essa ferramenta. Por exemplo, não é possível fragmentar um componente em vários para associar partes do mesmo a tempos diferentes de execução. Já na navegação e visualização possui diversificados recursos, onde é possível navegar em 3D com controle de velocidade e realismo (por exemplo, é permitido ao usuário descer escadas, agachar sob objetos e utilizar um "avatar" para representar a si próprio). É possível combinar coordenação espacial com o planejamento da construção por meio da simulação 4D e análise. Para as saídas (outputs), esse software permite identificação, inspeção e elaboração de relatórios de interferências encontradas no modelo 3D composto. Além disso, verifica automaticamente conflitos entre objetos em movimento. Possui recurso de "auditoria" que registra o status dos confrontos, como eles são identificados e qual a disposição tomada para os mesmos.

$$
\text { O SOLIBRI MODEL CHECKER }{ }^{\text {тм }}{ }^{2} \text { é um }
$$

produto da Solibri, Inc. que analisa a construção de modelos de informações para a segurança, qualidade, integridade física dos empreendimentos. A capacidade de importação de arquivos é baseada no padrão de formato de IFC. A ferramenta possui interface de boa qualidade, permite o uso de filtros e aplicar regras personalizadas para verificação do modelo. A ferramenta avalia restrições paramétricas, faz detecção de conflitos, permite a estimativa de quantidades e custos e geração de relatórios em RTF, PDF e XML. A reorganização dos componentes do modelo não é possível por essa ferramenta. Já na navegação e visualização, esses recursos são facilitados pelo sistema que oferece uma visualização através de visões em raio- $X$ (transparências) e um walk-in intuitivo e funcional, proporcionando ao modelo de construção a representação de potenciais falhas e interferências no projeto. E para as saídas (outputs) destacam-se os componentes conflitantes visualizados e verificações que o modelo está de acordo com as normas técnicas de construção e as melhores práticas da organização.

O SYNCHRO PROFESSIONAL ${ }^{3}$ é uma ferramenta de planejamento da Synchro Software. É utilizado em projetos de construção complexos . É composto pelos módulos de: cronograma, visualizador de modelo, banco de dados, servidor e computação na nuvem. Em termos da capacidade de importação de arquivos tem interoperabilidade com arquivos de múltiplas ferramentas CAD e BIM e também com diversas ferramentas de planejamento. A reorganização dos componentes do modelo é possível por essa ferramenta devido ao seu processo de modelagem. Esses objetos são ligados através de uma interface visual e de gestão de um único computador ou servidor para acesso multiusuário. Já na navegação e visualização, essa ferramenta suporta recursos diferenciados de visualização dos componentes durante animação da construção. E para as saídas (outputs) faz análise analítica de dados, emite relatórios, permite a criação de apresentações do tipo slide-show e faz a produção de vídeos.

\footnotetext{
${ }^{1}$ http://www.autodesk.com/products/autodesk-navisworks-family/overview

${ }^{2}$ http://www.solibri.com/solibri-model-checker.html

${ }^{3}$ http://synchroltd.com
} 
A partir da descrição das ferramentas integradoras selecionadas verifica-se um leque de funcionalidades resumidas na Tabela 1. Esta classificação permite hierarquizar as ferramentas estudadas na ordem de mais integradoras para menos integradoras, estando o Synchro em primeiro para essa questão, o Naviswork, em segundo e o Solibri, em terceiro. Esta baixa classificação da ferramenta Solibri, como uma ferramenta integradora, está neste estudo relacionada a sua ênfase na validação funcional em projeto, como indicado por Eastman et al. (2011), realizado por meio de checagem do projeto por regras que indicam conflitos físicos e dinâmicos.

Vislumbra-se então o cenário de colaboração entre os agentes do processo de projeto de AEC conforme a Figura 5, inspirado no esquema apresentado por Reinhardt (2011). Neste cenário pode-se imaginar no fluxo de informação o trânsito de modelos de informação, a priori internamente no contexto de cada agente do processo de projeto entre ferramentas de modelagem paramétrica (pré-dimensionamento) e de análise e simulação (avaliação do desempenho e crítica do dimensionamento). Após afinamento do modelo por cada agente os mesmos são então submetidos a coordenação de projeto para compatibilização. Consolida-se o modelo de informação composto. Neste processo são emitidos relatórios que são compartilhados com todos os agentes envolvidos e se reinicia o processo de modelagem e análise. $\mathrm{O}$ ciclo ser repete até que o modelo consolidado seja aprovado.

TABELA 1: Ferramenta Integradora.

\begin{tabular}{cccc}
\hline $\begin{array}{c}\text { PRINCIPAIS } \\
\text { FUNCIONALIDADES }\end{array}$ & NAVISWORK & SOLIBRI & SYNCHRO \\
\hline Reorganizar o modelo & $\mathrm{X}$ & $\mathrm{X}(\mathrm{ifc})$ & $\mathrm{X}$ \\
\hline $\begin{array}{c}\text { Integração de múltiplos } \\
\text { modelos criando modelo } \\
\text { composto }\end{array}$ & $\mathrm{X}$ & $\mathrm{X}$ & $\mathrm{X}$ \\
\hline $\begin{array}{c}\text { Navegação e visualização } \\
\text { Identificação de conflitos } \\
\text { (físicos - F, temporais - T, } \\
\text { dinâmicos - D) }\end{array}$ & $\mathrm{F}, \mathrm{T}, \mathrm{D}$ & $\mathrm{Fe} \mathrm{D}$ & \\
\hline $\begin{array}{c}\text { Emissão de relatórios e } \\
\text { marcações sobre o modelo }\end{array}$ & $\mathrm{X}$ & $\mathrm{X}$ & $\mathrm{X}$ \\
\hline
\end{tabular}




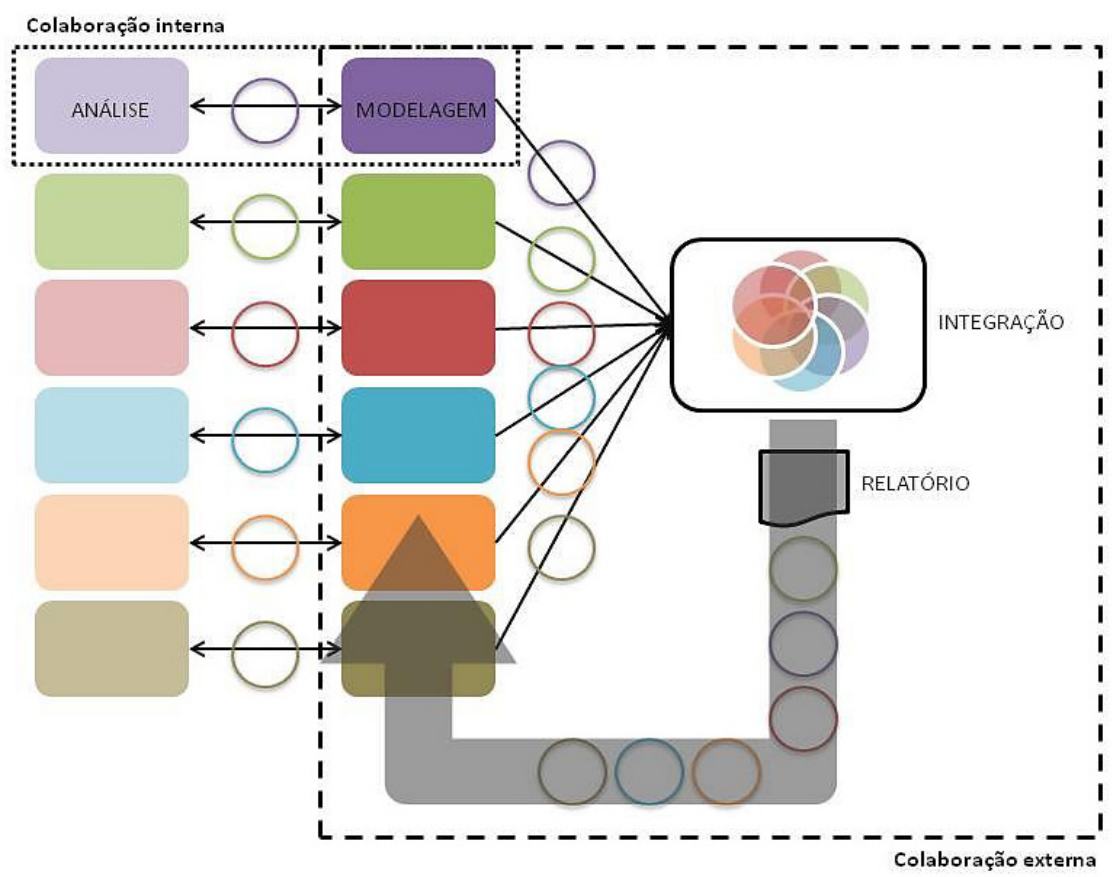

FIGURA 5: Processo de projeto BIM incluindo ferramenta integradora para a consolidação de múltiplos modelos.

Fonte: Adaptado de Reinhardt (2011).

\subsection{FERRAMENTAS COMPARTILHADORAS DE MODELOS}

O preenchimento das lacunas de comunicação dentro dos processos de projetos é latente. Como evidenciado, muitos problemas de interferências, retrabalhos e desperdícios derivam da solução desta questão. Neste contexto, as ferramentas compartilhadoras de modelos se apresentam como um possível instrumento que auxiliará: no aprimoramento das vias de comunicação, na criação de um ambiente colaborativo e no suporte nas tomadas de decisões. A colaboração ocorre pelo compartilhamento de modelos de informação da construção apoiando o processo de tomada de decisão.

O modelo de informação pode ser compartilhado por meio de quatro formas diferentes de trocas de arquivos, definindo diferentes níveis de colaboração (ISIKDAG; UNDERWOOD, 2009). Estas formas de troca de modelos BIM podem ser: (1) troca física de arquivos, (2) compartilhamento entre aplicativos, (3) compartilhamento em banco de dados centralizado ou (4) em banco de dados federativos. A primeira forma de colaboração é a mais simples e também a mais ineficiente; o modelo BIM é salvo numa mídia física e distribuído entre participantes do processo de projeto. Este formato de colaboração permite, como no processo de projeto tradicional, a proliferação de versões de modelos inconsistentes entre si. Esta forma de compartilhamento está implícita no esquema de colaboração representado na Figura 2. A segunda forma de colaboração já é mais evoluída e precisa, mas ainda limitada ao contexto de aplicações computacionais e disciplinas específicas, pois requer ligações diretas entre aplicativos. A terceira e quarta forma de colaboração são mais abrangentes, pois permitem a colaboração ampla, distribuída e precisa ao mesmo tempo. O modelo de informação é encapsulado num sistema de banco de dados que mantém sua integridade num contexto de edição síncrona e assíncrona por múltiplos agentes. O sistema de banco de dados pode ser centralizado e único ou distribuído e composto por múltiplos bancos de dados (federativo).

Em Eastman et al. (2011, p. 136-148), aponta que para a troca de arquivos de modelo de informação necessita-se evoluir dos repositório de documentos para os servidores de modelo. Esse mesmo autor estabelece os requisitos básicos para esses tipos de ambiente, sendo: controle de acessos, controle de usuários, saber 
ler-escrever-armazenar múltiplos formatos de modelos, controle de transações e controle de versões do modelo, suporte a biblioteca de componente, controle da documentação de projeto, suporte a comunicação assíncrona não estruturada entre usuários e outros. Estes autores listam as seguintes ferramentas com estas funcionalidades: Autodesk Collaborative Project Management, Bentley ProjectWise Integration Server, i-Model, ProjectWise Navigator, BIM Server, Drofus, EuroSTEP Share-A-Space Model Server, Graphisoft ArchiCad BIM Server, Horizontal Glue ${ }^{T M} 4$, Jotne EDM Model Server, Oracle Primavera $e$ AutoViewDois. Selecionou-se dentre estas, para este estudo, as ferramentas BIM Server $e$ EDMmodelServer que dão suporte à colaboração externa compartilhando modelos BIM no formato aberto (IFC - Industry Foundation Classes). Estas são ferramentas similares, entretanto a primeira é desenvolvida e distribuída como opensourse e a segunda é proprietária. Incluiu-se aqui também uma terceira ferramenta, o conjunto REVIT Serve $e$ Autodesk Project Bluestreak, pois permitem a colaboração interna entre agentes de uma mesma disciplina viabilizando a edição segmentada e distribuída de um mesmo modelo de informação.

O Revit Server é um aplicativo da AUTODESK, disponível para o conjunto de aplicativos Revit (Architecture, Structure e MEP). A criação do servidor BIM está vinculada ao fato de que este desempenha o papel de um servidor central único, que se comunica com diversos servidores remotos. Nas ferramentas do pacote, existem opções de trabalho colaborativo: enquanto a worksharing permite a múltiplos usuários acesso simultâneo a um modelo compartilhado através do uso de uma central, onde cada pessoa trabalha com uma cópia local e conforme modifica o elemento, vai sincronizando com a central, a opção linkedmodels é capaz de envolver diversas disciplinas, em que cada representante pode desenvolver sua especialidade e posteriormente vinculá-las a outras, acompanhando as mudanças ocorridas. Portanto, quando um usuário opta por sincronizar as modificações com o arquivo central, o servidor irá

\footnotetext{
${ }^{4}$ Recentemente renomeada BIM 360 Glue.

${ }^{5}$ http://bimserver.org.
}

substituir essas e permitir que os outros usuários, ao solicitarem a opção reload latest, tenham em seu arquivo local todas últimas modificações. Por fim, o aplicativo com o plug-in chamado Revit Stream funcionará em sincronia com o Autodesk Project Bluestreak, e dará suporte no canal de comunicação. Disponível em http://wikihelp.autodesk.com/Revit/.

O projeto Autodesk Bluestreak é uma solução de colaboração baseada em cloud computing, que permite às equipes de projeto de AEC, colaborar e coordenar seu trabalho com eficiência. Combina funcionalidades de compartilhamento de arquivos até notificações instantâneas de mudanças. O ambiente está disponível em http://bluestreak.autodesk.com. As funcionalidades oferecidas por meio do serviço em cloud computing são: gestão de usuários, escolha na definição de grupo de trabalho por meio de organização de diretório específico e a sincronização de modelos de informação nas ferramentas de autoria Revit. A interface ambiente é estruturada de modo semelhante ao utilizado pelas redes sociais, isto é existe um campo com todos os comentários e ações realizadas e outro com todas as conexões de usuários e um último referente aos grupos que compartilham informações. Esta abordagem permite diálogo informal entre os usuários e quando o aplicativo é instalado no desktop, as notificações são instantâneas podendo-se manter conversas entre projetistas em tempo real.

O BIM Server ${ }^{5}$ é uma plataforma opensource de colaboração baseada no padrão IFC. O sistema faz a integração de modelos BIM mantido num repositório das informações de construção onde arquivos IFC são interpretados por um núcleo e armazenados em um banco de dados. A ferramenta possibilita consultas, junção com detector de interferências e filtros de modelos, além do suporte a múltiplos usuários; várias pessoas podem trabalhar em suas respectivas partes, enquanto a base é atualizada em tempo real. Os envolvidos podem receber notificações das mudanças. 
EDMmodelServer é uma plataforma de colaboração que suporta o padrão IFC, desenvolvida pela empresa Jotne EPM Technology. Oferece ferramentas de exportação/importação, visualização e análise dos modelos, baseado na tecnologia Express Data Manager (EDM), trata-se de um produto de banco de dados, onde a sua estrutura é definida pela linguagem Express. As funções de gestão de segurança possibilitam configurações de acesso aos diretórios, usuários e grupos. Diferentes direitos de acesso à informação podem ser definidos: criar, excluir, visualizar, etc. A interface do usuário consiste em duas partes principais: uma janela dispondo das informações textuais e um visualizador do modelo (através do plug-in Octaga Modeller). Ao usuário, é disposto informações como: repositório com os diferentes modelos, árvore IFC com as diferentes hierarquias, relatórios do projeto e detalhes dos objetos. A ferramenta ainda permite a sincronização dos modelos das diferentes disciplinas de projeto. Isto inclui a capacidade de fazer upload de novos IFCs, substituir arquivos, fundir arquivos (check-in), downloads parciais e completos (check-out) (TAYLOR et al. 2009). O EDMmodelServer ${ }^{6}$ permite armazenar seus dados em padrões abertos buildingSMART. Pode criar validações e verificações, extraindo e mesclando modelos parciais, para encontrar os dados necessários para a sua tomada de decisão.

A partir da descrição das ferramentas compartilhadoras selecionadas verifica-se um leque de funcionalidades resumidas na Tabela 2 . Percebese que não há diferenciação entre as funcionalidades analisadas, onde as três ferramentas ofertadas viabilizam o seu uso.

Vislumbram-se dois possíveis cenários de colaboração (modelo segmentado e múltiplos modelos) entre os agentes do processo de projeto de AEC apresentados na Figura 6. Em ambos os cenários os modelos de informação não mais circulam livremente entre agentes, mas ao contrário são centralizados. Observa-se o compartilhamento segmentado de um único modelo e o compartilhamento integrado de múltiplos modelos. No compartilhamento segmentado a ferramenta de compartilhamento da suporte a edição compartilhada de um mesmo modelo entre múltiplos projetista. No compartilhamento integrado de múltiplos modelos a função da ferramenta é de repositório de modelos incorporando funções de integração entre modelos, portanto consolidação dos mesmos.

TABELA 2: Ferramenta Compartilhadora.

\begin{tabular}{|c|c|c|c|}
\hline FUNCIONALIDADES & $\begin{array}{l}\text { REVIT-SERVER / } \\
\text { BLUESTREAK }\end{array}$ & BIM-SERVER & EDMmodelServer \\
\hline $\begin{array}{c}\text { Gestão de usuários } \\
\text { (Estrutura hierárquica de } \\
\text { administração e registro de acesso) }\end{array}$ & $\mathrm{X}$ & $\mathrm{X}$ & $\mathrm{X}$ \\
\hline $\begin{array}{c}\text { Banco de Dados que consolida } \\
\text { modelos (com controle de } \\
\text { transações) }\end{array}$ & $x$ & $x$ & $x$ \\
\hline Controle de versões & $\mathrm{X}$ & & $x$ \\
\hline $\begin{array}{c}\text { Compartilhamento de documentos } \\
\text { e relatórios }\end{array}$ & $X^{*}$ & $x$ & $x$ \\
\hline Recursos de visualização & $X^{*}$ & $x$ & $x$ \\
\hline Trabalho distribuído em tempo real & $x$ & $x$ & $x$ \\
\hline
\end{tabular}

*Nota: Apenas para o Bluestreak e também o único que faz comunicação síncrona entre partes envolvidas

\footnotetext{
${ }^{6}$ http://www.epmtech.jotne.com/
} 


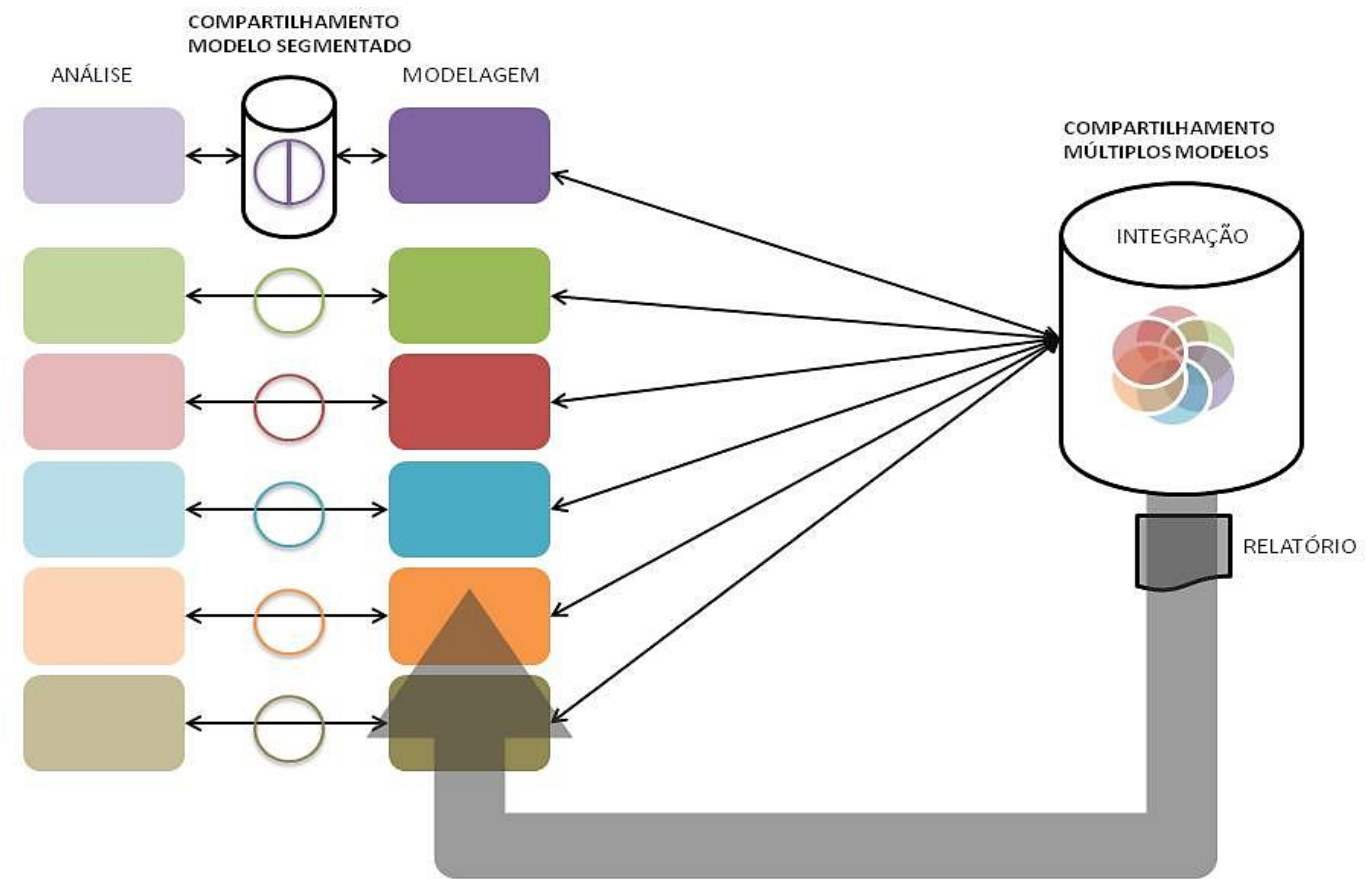

FIGURA 6: Processo de projeto BIM incluindo ferramenta compartilhadora para suporte a edição um mesmo modelo entre diferentes projetistas (cenário 1) e para suporte agregado de repositório e consolidação de múltiplos modelos (cenário 2).

\subsection{MAPEAMENTO DO FERRAMENTAL CONTEXTUALIZADO NA COORDENAÇÃO DE PROJETOS}

É possível compreender funções de compartilhamento como a gestão de usuários (registro de acesso), a visualização das transações sobre o banco de dados e versões do desenvolvimento do modelo de informação composto, o acesso aos relatórios de consolidação do modelo e a comunicação síncrona - como sendo recursos que subsidiam atividades de gerenciamento do projeto do tipo: acompanhamento das providências operacionais, tomada de decisões e controle do processo (Tabela 3). Desta forma, se evidencia que no âmbito de gerenciamento de projetos há predominância do uso de ferramentas compartilhadoras.

Já na atividade de coordenação técnica este estudo evidenciou um apoio balanceado de ferramentas integradoras e compartilhadoras; principalmente se a ferramenta de compartilhamento incorporar funcionalidades de análise de interferência entre modelos (Tabela 4). A coordenação técnica ao analisar soluções de projeto necessitará navegar pelo modelo composto e avaliar soluções propostas para conflitos marcados. A coordenação técnica ao identificar e caracterizar interfaces e coordenar o fluxo de informações entre os agentes intervenientes necessitará dos recursos de gestão de usuários, controle de transações sobre o banco de dados, controle de versões do desenvolvimento do modelo composto, como também possibilitará visualizar o modelo, gerar relatórios e comunicarse, assíncrona e sincronamente, com os agentes envolvidos. Desta forma, é também usuária de ferramentas integradoras.

Finalmente, este estudo evidenciou que a compatibilização de projeto é essencialmente apoiada por ferramentas integradoras. Isto ocorre, pois as atividades de compatibilização compostas pela verificação da construtibilidade, identificação das interferências e resolução de pendências e conflitos é apoiada na sua maioria pelas funcionalidades de ferramentas integradoras (Tabela 1). Se o modelo é remotamente compartilhado cabe ao compatibilizador liberar o modelo para os agentes envolvidos após ter finalizado a integração, sendo assim também faz uso da ferramenta compartilhadora restringindo o acesso ou liberando o acesso do modelo para consulta ou descarregamento (Tabela 5). 
TABELA 3: Gerenciamento de projetos x uso de ferramentas de compartilhamento e integração.

\section{Gerenciamento de Projetos}

Ferramentas

integradora
Ferramenta compartilhadora

\begin{tabular}{cc}
\hline $\begin{array}{c}\text { Encaminhamento e acompanhamento das } \\
\text { providências operacionais }\end{array}$ & $\mathrm{X}$ \\
\hline Tomada de decisões de caráter gerencial & $\mathrm{X}$ \\
\hline Controle do processo & $\mathrm{X}$ \\
\hline
\end{tabular}

\section{TABELA 4: Coordenação técnica $x$ uso de ferramentas de compartilhamento e integração.}

\begin{tabular}{ccc} 
Coordenação técnica & $\begin{array}{c}\text { Ferramentas } \\
\text { integradora }\end{array}$ & $\begin{array}{c}\text { Ferramenta } \\
\text { compartilhadora }\end{array}$ \\
\hline $\begin{array}{c}\text { Estabelecnicos } \\
\text { técnto de diretrizes e parâmetros } \\
\text { técnicas a serem solucionadas }\end{array}$ & $\mathrm{X}$ & $\mathrm{X}$ \\
\hline $\begin{array}{c}\text { Coordenação do fluxo de informações entre os } \\
\text { agentes intervenientes }\end{array}$ & $\mathrm{X}$ \\
\hline Análise das soluções técnicas & $\mathrm{X}$ & $\mathrm{X}$ \\
\hline
\end{tabular}

TABELA 5: Compatibilização de projetos x uso de ferramentas de compartilhamento e integração.

\begin{tabular}{ccc} 
Compatibilização de Projetos & $\begin{array}{c}\text { Ferramentas } \\
\text { integradora }\end{array}$ & $\begin{array}{c}\text { Ferramenta } \\
\text { compartilhadora }\end{array}$ \\
\hline Verificação da construtibilidade & $\mathrm{X}$ \\
\hline $\begin{array}{c}\text { Identificação das interferências: físicas, temporais } \\
\text { (estáticas ou dinâmicas) }\end{array}$ & $\mathrm{X}$ & $\mathrm{X}$ \\
\hline Resolução de pendências e conflitos & $\mathrm{X}$ & \\
\hline Liberação dos projetos &
\end{tabular}

Entretanto, deve-se observar que a instalação, configuração e manutenção das ferramentas de compartilhamento e integradoras não necessariamente é responsabilidade do gerente de projeto, da coordenação técnica ou da compatibilização. A literatura indica que no processo de projeto com BIM novos papéis especializados em TI e em modelo de informação surgem (ANDRADE e AMORIN, 2011; GU e LONDON, 2010; BARINSON e SANTOS, 2010). Entre os quais podem-se destacar profissionais BIM que atuam em contextos que oferecem suporte ao mercado de AEC tais como: consultoria, indústria de software e ambientes de construção virtual (universidades, institutos de pesquisas e agências governamentais), sendo que pode variar conforme 
o tamanho da empresa, nível organizacional e localmente ao nível de escritório/construtora ou mesmo atuar no nível de projeto (BARINSON; SANTOS, 2011).

Segundo Barinson e Santos (2011), num estudo abordado com empresas em São Paulo, quanto à mudança de papéis, os projetistas (arquiteto e engenheiro) passam a ser Modeladores BIM. O proprietário das pequenas empresas assume as funções do Gerente BIM. Nas empresas de porte médio é o proprietário ou o diretor que desempenha o papel do Gerente BIM do escritório, ficando a cargo do Coordenador de Projetos ou do Gerente Técnico o papel do Gerente do Modelo. Nas grandes empresas o Gerente de $\mathrm{TI}$ ou um especialista em BIM assumem o papel do Gerente BIM da Construtora/Escritório e Gerente do Modelo/Projeto. Nas grandes empresas é o Gerente BIM da Construtora/ Projeto que está assumindo o papel de gerenciamento do processo de projeto BIM. Cargos de Analista BIM e Facilitador BIM ainda não estão sendo demandados porque as atividades de análise e simulações de modelos, assim como manipulação e visualização do modelo no canteiro de obras, ainda não são atividades desenvolvidas pela grande maioria das empresas. A Tabela 6 resume os benefícios propiciados por ferramentas integradoras e compartilhadoras para o processo de projeto colaborativo mediado por BIM buscando atender critérios de integração, colaboração, coordenação, análise, documentação e navegação. Os benefícios proporcionados pelas ferramentas integradoras vão desde a consolidação de múltiplos modelos de informação até interação do usuário como o modelo. Os benefícios que puderam ser observados e que são proporcionados pelas ferramentas compartilhadoras vão desde a interconexão entre envolvidos até a coalizão de interesses.

Para Tálamo e Carvalho (2010), o tempo de amadurecimento de uma rede de cooperação empresarial é outro fator crítico ao sucesso do compartilhamento. Ao longo do tempo, os integrantes identificam novas oportunidades de compartilhamento, ao mesmo tempo, que estabelecem laços fracos, fundamentais ao fluxo da informação e conhecimento. O tempo de amadurecimento necessário à rede implica em poucos resultados imediatos e o cumprimento do amadurecimento da rede é viabilizado em função do caráter motivacional dos integrantes.

Taylor e Bernstein (2009) identificam também que com o aumento da prática de BIM evolui a trajetória das empresas de AEC em quebrar paradigmas e partilhar arquivos eletrônicos que suportem BIM em todo o processo de projeto e para alimentar a cadeia inter-organizacional, aprimorando assim a integração e o compartilhamento de informação do modelo BIM.

TABELA 6: Benefícios resultantes do uso de ferramentas compartilhadoras e de integração no processo de projeto com BIM.

\begin{tabular}{|c|c|c|}
\hline Critério & Ferramenta integradora & Ferramenta compartilhadora \\
\hline Integração & $\begin{array}{l}\text { Gera um modelo consolidado a partir } \\
\text { de múltiplos modelos de informação }\end{array}$ & $\begin{array}{l}\text { Todos envolvidos estão inter- } \\
\text { conectados automaticamente }\end{array}$ \\
\hline Colaboração & $\begin{array}{l}\text { Centraliza as informações e gera } \\
\text { maior consistência dos dados }\end{array}$ & $\begin{array}{c}\text { Atualiza, importa e exporta } \\
\text { modelos/arquivos do banco de dados }\end{array}$ \\
\hline Coordenação & $\begin{array}{c}\text { Suporte nas tomadas de decisões } \\
\text { técnicas e gerenciais }\end{array}$ & Comunicação em tempo real \\
\hline Análise & Identificação de interferências & Análise do fluxo da informações \\
\hline Documentação & $\begin{array}{l}\text { Emite relatórios de conflitos, } \\
\text { animações (percurso, } \\
\text { comportamento, 4D) }\end{array}$ & $\begin{array}{c}\text { Compartilhamento de documentos } \\
\text { técnicos, arquivos diversos e } \\
\text { notificações }\end{array}$ \\
\hline Navegação & $\begin{array}{l}\text { Permite ao usuário interagir com e } \\
\text { dentro do modelo }\end{array}$ & Suporte na coalizão de interesses \\
\hline
\end{tabular}




\section{CONSIDERAÇÕES FINAIS}

O objetivo deste trabalho foi explorar na gestão de projeto de Arquitetura, Engenharia e Construção com BIM o papel das ferramentas de integração e compartilhamento remoto de modelos de informação. O mapeamento realizado entre funcionalidades das ferramentas integradoras e compartilhadoras estudadas e as atividades de gerenciamento de projeto, coordenação técnica e compatibilização permitiu esclarecer e evidenciar o perfil de suporte em BIM necessário para cada um dos respectivos papéis. Verificou-se que o gerenciamento de projeto é melhor subsidiado por ferramentas compartilhadoras, que a coordenação técnica faz uso balanceado das ferramentas compartilhadoras e integradoras, e, que a compatibilização é essencialmente apoiada por ferramentas integradoras. Esta explicitação pode subsidiar esforços de treinamento e implementação de BIM, assim como direcionar aquisições de TI para cada um dos papéis de gestão de AEC.

A partir da descrição das ferramentas NAVISWORK, SOLIBRI e SYNCHRO verificou-se um leque de funcionalidades distintas permitindo hierarquizar as ferramentas na ordem de mais integradoras para menos integradoras, estando o Synchro em primeiro para essa questão, o Naviswork, em segundo e o Solibri, em terceiro. .

Entre as ferramentas compartilhadoras estudadas REVIT SERVER \& BLUESTREAK, BIMSERVER e EDMmodelServer percebe-se que não há diferenciação entre as funcionalidades analisadas, onde as três ferramentas ofertadas viabilizam o seu uso. Entretanto, a diferenciação está no formato de modelo compartilhado, sendo que a primeira o formato é proprietário e para as duas últimas o formato é aberto (IFC).

Três esquemas de colaboração para a etapa de desenvolvimento do produto foram vislumbrados. Cada modelo representou um uso, variando da menor para a maior utilização das ferramentas estudadas alterando-se assim formas de compartilhamento e troca de modelos BIM. Esquematizou-se um projeto colaborativo com BIM, uso exclusivo de ferramenta integradora e a troca física de arquivos (Figura 4). Por fim, definiu-se o esquema de trabalho em projeto colaborativo com BIM, com uso de ferramenta integradora e compartilhadora; portanto, o compartilhamento em banco de dados centralizado (Figura 5). Estes esquemas propõem melhor exemplificar o uso integrado de ferramentas BIM de autoria e de integração no processo de projeto colaborativo de AEC na busca de vencer o desenvolvimento de projeto discretizado, individualista e fracamente acoplado. Incentivando mudanças no sentido holístico de desenvolvimento de projeto.

\section{REFERÊNCIAS BIBLIOGRÁFICAS}

ACHTEN, H.; BEETZ, J. What Happened to Collaborative Design? In: CONFERENCE ON EDUCATION AND RESEARCH IN COMPUTER AIDED ARCHITECTURAL DESIGN IN EUROPE. 27., 2009, Istanbul. Proceedings ... Istanbul: eCAADe \& ITL/YTU: 358-365 p. 2009.

ANDRADE, B.S de ; AMORIN, S.R.L. de . Alterações metodológicas na gestão de processo de projeto aplicada com a utilização de Software tipo BIM. In: SIMPÓSIO BRASILEIRO DE QUALIDADE DE PROJETO. 2., 2011, Rio de Janeiro. Anais .... Rio de Janeiro : PROARQIAU/UPS, 2011. p. 790-799.

ANDRADE, M.L.V.X. de ; RUSCHEL, R. C. . O processo digital de geração da forma baseado no desempenho com suporte em BIM: o caso do Smithsonian Institution Courtyard Enclosure. In: SIMPÓSIO BRASILEIRO DE QUALIDADE DE PROJETO. 2., 2011, Rio de Janeiro. Anais .... Rio de Janeiro : PROARQ-IAU/UPS, 2011. p. 131-144

BARISON, M. B.; SANTOS, E. T. An overview of BIM specialists. In: INTERNATIONAL CONFERENCE ON COMPUTING IN CIVIL AND BUILDING ENGINEERING, 2010, Nottingham. Proceedings... Nottingham: Nottingham University Press, 2010. p. 141. Disponível em: <http://www.engineering.nottingham.ac.uk/icccbe /proceedings/pdf/pf71.pdf>. Acesso em 21 mar. 2012.

BARINSON, M.B.; SANTOS, E.T. Atual cenário da implementação de BIM no mercado da construção civil da cidade de São Paulo e demanda por especialistas, In: ENCONTRO DE TECNOLOGIA DE INFORMAÇÃO E COMUNICAÇÃO NA CONSTRUÇÃO, 5.,2011, Salvador. Anais... Salvador:BIM - Modelando a construção do future, 2011.

BERTELSEN, S. Bridging the gaps - towards a comprehensive understanding of lean construction. In: Proceedings IGCL-10. Gramado, 2002.

BETTS, M. Strategic Management of I.T in Construction. Londres: Blackwell Science, 1999. 
CAMBIAGHI, H.; AMÁ, R.; CASTANHO, M.; WESTERMANN, M. Diretrizes Gerais para Intercambialidade de Projetos em CAD: Integração entre Projetista, Construtoras e Clientes. São Paulo: PINI, 2002. 44 p.

COELHO, S; NOVAES, C. Modelagem de Informações para Construção (BIM) e ambientes colaborativos para gestão de projetos na construção civil. Revista Gestão \& Tecnologia de Projetos, São Paulo, v.3, n.1, p. 44-48, 2008.

DAWOOD, N; SRIPRASERT, E.; MALLASI, Z; HONNS, B. 4D visualization development: Real Life Case Studies. In: INTERNATIONAL COUNCIL FOR RESEARCH AND INNOVATION IN BUILDING AND CONSTRUCTION. CIB W78 conferência. Aarhus School of Architecture, 2002.

EASTMAN, C.; TEICHOLZ, P.; SACKS, R.; LISTON, K. BIM Handbook: A guide to Building Information Modeling for owners, managers, designers, engineers, and contractors. Hoboken, New Jersey: John Wiley \& Sons, 2008. $490 \mathrm{p}$.

EASTMAN, C.; TEICHOLZ, P.; SACKS, R.; LISTON, K. BIM Handbook: A guide to Building Information Modeling for owners, managers, designers, engineers, and contractors. 2. ed. Hoboken, New Jersey: John Wiley \& Sons, 2011. 589 p.

FAVARETTO,F. Melhoria da qualidade da informação no controle da produção: estudo exploratório utilizando Data Warehouse. Gestão \& Produção, v. 17, n. 2, p. 343353, Maio/Ago. 2007

GRAZIANO, F. P. Compatibilização de Projetos. São Paulo: Instituto de Pesquisa Tecnológica de São Paulo IPT-SP (Mestrado Profissionalizante), 2003.

GU, N.; LONDON, K. Understanding and facilitation BIM adoption in the AEC industry. Automation in Construction, v. 19, n. 8, p. 988-999, Dec. 2010.

HAMID, B. Mapping Design Process into Process Design: Implementing Collaborative Design from Social Psychological Approaches. In: CONFERENCE ON EDUCATION IN COMPUTER AIDED ARCHITECTURAL DESIGN IN EUROPE, 24, Frankfurt. Procedings ..., Frankfurt:eCAADe, , p. 711-716. 2007.

HEESOM, D.; MAHDJOUBI, L. Technology Opportunities and Potential for the Virtual Construction Site - Volume 1: Emerging Research Initiatives. Universidade de Wolverhampton, 2003.

ISIKDAG, U.; UNDERWOOD, J. Two design patterns for facilitating Building Information Model-based synchronous collaboration. Automation in Construction, v. 19, n. 5, p. 544-553, Kidlington, 2009.

JACOSKI, C. A; LAMBERTS, R. A interoperabilidade como fator de integração de projetos na construção civil. In: WORKSHOP NACIONAL GESTÃO DO PROCESSO DE PROJETO NA CONSTRUÇÃO DE EDIFÍCIOS, 2., 2002, Porto Alegre, RS. Anais .... Porto Alegre, 2002.
LAURINDO, F.J.B.,SHIMIZU,T.,CARVALHO,M.M. de, RABECHINI JR, R.O papel da Tecnologia da Informação (TI) na estratégia das organizações. Gestão \& Produção v.8, n.2, p.160-179, São Carlos, ago. 2001

MORAES, R.O.; LAURINDO, F.J.B.Um estudo de caso de gestão de portfólio de projetos de Tecnologia da Informação. Gestão \& Produção v.10, n.3, p.311-328, São Carlos, dez. 2003

KALAY, Y.E. The impact of information technology on design methods, products and practices. Design Studies, v. 27, n. 3, p. 357-380, May 2006.

KVAN, T. Collaborative design: what is it? Automation in Construction, v. 9, n. 4, p. 409-415, Kidlington, July 2000.

NITITHAMYONG, P; SKIBNIEWSKI, M. Web-based construction project management systems: how to make them successful? Automation in construction, 13(4), pp. 491-506, Kidlington, 2004.

PICHI, F.A. Oportunidades da aplicação do Lean Thinking na construção. Revista Ambiente Construído, v. 03, p. 723, Porto Alegre, 2003.

REINHARDT, J. BIM no processo de projeto e integração com planejamento e execução de obra. In: SEMINÁRIO BIM - MODELAGEM DA INFORMAÇÃO, 2., 2011, São Paulo, SP. Anais.... São Paulo, 2011.

SANTOS, A. POWELL, J. FORMOSO, C. T. Transferência de Know-How no ambiente da Construção Civil. In: ENCONTRO NACIONAL DE TECNOLOGIA DO AMBIENTE CONSTRUÍDO, 2., 1998, 801p. p. 9-17. Universidade Federal de Santa Catarina: Florianopólis, SC. Anais....Florianópolis, 1998.

SILVA, M.A.C.; SOUZA, R. DE. Gestão do processo de projeto de edificação. São Paulo: O Nome da Rosa, 2003. $181 \mathrm{p}$.

SIMOFF ,S, J; MARY,L. M. Analysing participation in collaborative design environments. Design Studies, v 21 p. 119-144, 2000, Disponível em: <http: www.elsevier.com/locate/destud> Acesso em: 22 mar. 2012.

SOLANO, R. da S., Compatibilização de projetos na construção civil de edificações:

método das dimensões possíveis e fundamentais. In: ENCONTRO NACIONAL DE ENGENHARIA DE PRODUÇÃO, 25, 2005, . p. 2768-2773. Porto Alegre. Anais.... Porto Alegre: ABEPRO, 2005.

TAYLOR, C; NING, G et al. Collaboration Platform. Projeto de pesquisa 2007-003-EP. Brisbane, Austrália: Cooperative Research Centre for Construction Innovation, 2009. Disponível em: < http: www.construction-innovation.info_images_pdfs_2._ Final_Report_Edited_11.08.09>. Acesso em: 11 mar. 2012. 
TAYLOR, J.E.; BERNSTEIN, P.G. Paradigm Trajectories of Building Information Modeling. Journal of Management in Engineering (C) ASCE / APRIL 2009. Disponível em: <DOI: 10.1061/_ASCE_0742-597X_2009_25:2_69_> Acesso em 14 abr. 2012.

TOBIN, J. atomicBIM: Splitting Data to Unleash BIM's Power. AEC Bytes, Building the Future (Article), October 2008. Disponível em: < http://www.aecbytes.com/buildingthefuture/2008/atom icBIM.html> Acesso em: 16 abr. 2012. 